\title{
EDITORIAL
}

\section{The unnatural history of tetralogy of Fallot: surgical repair is not as definitive as previously thought}

\section{C van Doorn}

Heart 2002;88:447-448

Surgical correction of tetralogy of Fallot has proven very successful in the short term, although from longer term follow up it is increasingly apparent that many patients are haemodynamically compromised and their condition has not been cured

$\mathrm{T}$ etralogy of Fallot (TOF) is a complex congenital cardiac abnormality representing approximately $10 \%$ of all cardiac malformations. It has a pathophysiology characterised by a ventricular septal defect (VSD) and right ventricular outflow tract obstruction (RVOTO) causing a right-to-left-shunt with low pulmonary blood flow and cyanosis. The extent of the RVOTO is highly variable and may include hypoplasia and dysplasia of the pulmonary valve as well as obstruction at the subvalvar and pulmonary artery level. The RVOTO is progressive, as is the compensatory right ventricular hypertrophy that adds to the obstruction. Without specific surgical management up to $35 \%$ of children will die within the first year of life, $50 \%$ by the third year, and only few will survive into adulthood. ${ }^{1}$ With this dismal natural history, interventions to change the outcome are much needed.

In 1944, TOF was the first congenital heart lesion to be palliated ${ }^{2}$ and 10 years later also the first complex cardiac lesion to undergo successful open repair. ${ }^{3}$ Over the last decades, advances in paediatric cardiology, surgery, and intensive care have transformed the outlook for patients with TOF. Currently in the UK, surgical correction carries a 30 day mortality of less then 3\% (Central Cardiac Audit Database, personal communication, 2000-2001) and many operative survivors are expected to reach adulthood. Unfortunately, at long term follow up it is becoming increasingly clear that many patients are haemodynamically compromised and what was originally thought to be a definitive repair is in fact not a cure.

The principles of surgical correction of TOF involve closure of the VSD and relief of the RVOTO. To create an unobstructed way out of the right ventricle, pulmonary valvotomy, the insertion of an outflow tract patch or a transannular patch are often required. Consequently, most patients acquire pulmonary regurgitation as a result of the repair. While this is apparently well tolerated in the early postoperative years, it is now well established that in the long term chronic pulmonary regurgitation is associated with reduced exercise capacity, right ventricular dilatation, ventricular arrhythmias, and sudden death. Although recently the benefits of late pulmonary valve replacement for improving ventricular
WCIN 3JH, UK vanDoC@gosh.nhs.uk
Correspondence to: Dr Carin van Doorn, Ormond Street Hospital for function $^{4}$ and stabilising cardiac rhythm ${ }^{45}$ have been demonstrated, the indications and timing for this procedure remain to be defined.

\section{ACHIEVING PULMONARY COMPETENCE}

For many years cardiac surgeons have recognised the importance of achieving lasting pulmonary competence at the time of TOF repair, but various attempts to achieve this have so far failed. Construction of a biological or synthetic monocusp valve in the reconstructed right ventricular outflow tract proved disappointing because of early structural valve deterioration with subsequent pulmonary regurgitation. Also, the insertion of a pulmonary or aortic homograft at the time of repair provides only a temporary solution because of calcification and lack of growth of the homograft, leading to recurrent RVOTO. Lately, biological valve conduits have been marketed with the promise of "no calcification", but clinical trials are still at an early stage.

If normal pulmonary valve function cannot be achieved, then the second best option may be to try to minimise the extent of the pulmonary regurgitation by accepting the smallest possible annulus size that still gives adequate right ventricular unloading. This option is explored by Uebing and colleagues in this issue of Heart. ${ }^{6}$ In a study of patients with a median follow up time of 4.8 years after TOF repair they confirmed the well known facts that more extensive pulmonary regurgitation is associated with a larger postoperative pulmonary annulus and right ventricular size. More interestingly, no correlation was found between the right ventricle/left ventricle systolic pressure index and pulmonary annulus diameter indexed for body surface area. Even for patients with a pulmonary annulus index close to the fourth lower standard deviation, the right ventricular pressure load was not significantly elevated. This suggests that in many patients the annulus was larger than strictly necessary for adequate right ventricular unloading. The authors recommended that at the time of surgical repair the pulmonary annulus should be enlarged to only the second lower standard deviation of normal.

A problem with the study by Uebing and colleagues is that a model of pulmonary incompetence and right ventricular dilation is used to define the minimum adequate pulmonary diameter for surgical correction. At the time of the

Abbreviations: RVOTO, right ventricular outflow tract obstruction; TOF, tetralogy of Fallot; VSD, ventricular septal defect 
operation, however, the conditions are those of right ventricular hypertrophy and outflow tract obstruction. So, can the recommendation by Uebing and colleagues still be applied in this situation? This question is difficult to answer, in particular because of the wide variation in the muscle hypertrophy and RVOTO in TOF. At the pulmonary stenosis end of the spectrum there is often moderate annulus hypoplasia with obstruction at the level of the valve only. In these circumstances it is to be expected that valvotomy with conservative annular extension will provide adequate right ventricular unloading with little pulmonary regurgitation. In contrast, patients with pulmonary atresia type TOF often have a long segment infundibular stenosis with a small, dysplastic pulmonary valve. In these cases extensive infundibular resection and transannular patching may be required. The extent to which the RVOTO has to be relieved may be difficult to judge in the paralysed heart at the time of the operation, and residual obstruction may only manifest itself when the heart has regained its tone. To complicate matters further, this obstruction often has a dynamic component to it, ${ }^{7}$ which diminishes over time but is made worse by the use of inotropes. Residual RVOT is poorly tolerated in the immediate postoperative period and may necessitate revision of the repair during the same operation or early redo surgery. On the other hand, the hypertrophied right ventricle copes well with pulmonary regurgitation. Therefore if in doubt many surgeons will err on making the right ventricular outflow tract just a little bigger.

\section{OPTIMAL TIMING AND APPROACH}

The optimal timing and surgical approach for correction of TOF remain controversial. With increasing experience in the repair of many complex cardiac abnormalities in neonates and infants, there has been a move towards earlier primary correction of TOF. Arguments in support of this strategy include removal of the stimulus for right ventricular hypertrophy and fibrosis, alleviation of systemic cyanosis and, in symptomatic infants, avoidance of initial palliation with an arteriopulmonary shunt. Recent series of patients operated on in the first few months of life have shown excellent early and five year survival. ${ }^{8}$ A serious concern, however, was an increase in the use of transannular patches and right ventricle to pulmonary artery conduits; in one study $42 \%$ of patients required reoperation within five years for recurrent RVOTO or severe pulmonary incompetence. ' Careful long term follow up is required with emphasis on arrhythmias and right ventricular function to define the indications and benefits of early repair.

In conclusion, the outcome after surgical repair of TOF is far superior to the natural history of the disease, but the timing of surgery and operative techniques remain controversial. At present many patients with "repaired" TOF are left with haemodynamic defects that are poorly tolerated long term and may require further intervention. Therefore life long follow up at a congenital heart centre is mandatory.

\section{REFERENCES}

1 Campbell M, Deuchar DC, Brock RC. Results of pulmonary valvotomy and infundibular resection in 100 cases of Falllot's tetralogy. BM $1954 ; 2: 111-22$

2 Blalock A, Taussing HB. The surgical treatment of malformations of the heart in which there is pulmonary stenosis or pulmonary atresia. JAMA 1945; 128:189.

3 Lillehei CW, et al. Direct vision intracardial surgical correction of the tetralogy of Fallot, pentalogy of Fallot, and pulmonary atresia defects: report of the first ten cases. Ann Surg 1955;142:418-45.

4 Discigil B, Dearani JA, Puga FJ, et al. Late pulmonary valve replacement after repair of tetralogy of Fallot. J Thorac Cardiovasc Surg $2001 ; 121 ; 344-51$

5 Therrien J, Siu SC, Harris L, et al. Impact of pulmonary valve replacement on arrhythmia propensity later after repair of tetralogy of fallot, Circulation 2001;103:2489-94.

6 Uebing A, Fischer $G$, Bethge $M$, et al. Influence of the pulmonary annulus diameter on pulmonary regurgitation and right ventricular pressure load after repair of tetralogy of Fallot. Heart 2002;88:510-14.
7 Wensley DF, Karl T, Deanfield JE, et al. Assessment of residual right ventricular outflow tract obstruction following surgery using the response to intravenous propranolol. Ann Thorac Surg 1987;44:633-6.

8 Hirsch JC, Mosca RS, Bove EL. Complete repair of tetralogy of Fallot in the neonate: results in the modern era. Ann Surg 2000;232:508-14.

9 Pigula, FA, Khalil PN, Mayer JE, et al. Repair of tetralogy of Fallot in neonates and young infants. Circulation 1999;100(suppl II):157-61.

\section{WEB TOP 10}

\section{www.heartjnl.com}

These articles scored the most hits on Heart's web site during August 2002

1 Acute myocardial infarction: reperfusion treatment F Ribichini, W Wijns

September 2002;88;298-305. (Education in Heart)

2 Antiplatelet treatment in unstable angina: aspirin, clopidogrel, glycoprotein IIb/IIla antagonist, or all three?

SA Harding, NA Boon, AD Flapan

July 2002;88: 11-14. (Viewpoint)

3 Cardiovascular and coronary risk estimation in hypertension management

EJ Wallis, LE Ramsay, PR Jackson

September 2002;88:306-12. (Education in Heart)

4 Adherence to statin treatment and readmission of patients after myocardial infarction: a six year follow up study

LWei, J Wang, P Thompson, S Wong, AD Struthers,

TM MacDonald

September 2002;88:229-33. (Cardiovascular medicine)

5 Off-pump coronary artery bypass surgery

PP Th de Jaegere, WJL Suyker

September 2002;88:313-18. (Education in Heart)

6 New insights into the mechanism of neurally mediated syncope

MA Mercader, PJ Varghese, SJ Potolicchio, GK Venkatraman SW Lee

September 2002;88:217-21. (Cardiovascular medicine)

7 Clinical outcomes of patients with diabetes

mellitus and acute myocardial infarction treated with primary angioplasty or fibrinolysis

LF Hsu, KH Mak, KW Lau, LL Sim, C Chan, TH Koh,

SC Chuah, R Kam, ZP Ding, WS Teo, YL Lim

September 2002;88:260-5. (Interventional cardiology and surgery)

8 Heart failure in the young

$M$ Burch

August 2002;88:198-202. (Education in Heart)

9 Long term efficacy and safety of atorvastatin in the treatment of severe type III and combined dyslipidaemia

$M$ van Dam, M Zwart, F de Beer, AHM Smelt, MH Prins,

MD Trip, LM Havekes, PJ Lansberg, JJP Kastelein

September 2002;88:234-8. (Cardiovascular medicine)

10 Arteriosclerotic renal artery stenosis: conservative versus interventional management

C Haller

August 2002;88:193-7. (Education in Heart)

Visit the Heart website for hyperlinks to these articles, by clicking on "Top 10 papers"

www.heartinl.com 